\title{
Innovations
}

\section{Cardiac rehabilitation programs: An investigation into the reasons for non-attendance in Qatar}

\section{Authors}

Nawal Ali Al-Ashwal'; Kim Critchley²*; Kathleen Benjamin

\section{Abstract}

Despite the many benefits of cardiac rehabilitation programs, participation of eligible patients in these programs can be low. Understanding the factors that prevent cardiac patients from attending these programs can provide healthcare professionals with insights on how to reduce the barriers and increase participation. The purpose of this quantitative descriptive study was to investigate the reasons why patients residing in Qatar do not attend cardiac rehabilitation (Phase 11). ' The target population were 850 patients who were referred to cardiac rehabilitation during an eight-month period in 2015, but who did not attend Phase 11 of the program. Individuals were invited to complete a phone survey which included socio-demographic questions and a pre-existing instrument called the Cardiac Rehabilitation Barriers Scale. Forty-six participants completed the phone survey in 2016. The most frequently reported barriers were: work responsibilities (56.5\%), time constraints (50\%), already exercising at home/community (39.1\%), distance to program (39.1\%), travel out of country (32.6\%), and not needing cardiac rehabilitation (32.6\%). Results of this study can be used to inform the development of new policies that will reduce the barriers and promote attendance. Future qualitative research can be done to gain deeper insights into the reasons for non-attendance.

\section{Keywords}

cardiac; exercise; adult; barriers; nursing; patient education

\section{Introduction}

Among non-communicable diseases, cardiovascular disease (CVD) is the leading cause of death worldwide and the leading cause of burden on the health care system. ${ }^{1,2}$ It is estimated that 17.3 million people die annually from CVD. ${ }^{2}$ In Qatar, CVD has been the leading cause of morbidity and mortality for over 20 years. ${ }^{.}$One possible reason for the increase prevalence of CVD in Qatar relates to changes in peoples' life style and living environment due to the rapid development of Qatar infrastructure. ${ }^{3,4}$ In the Middle East, people tend to

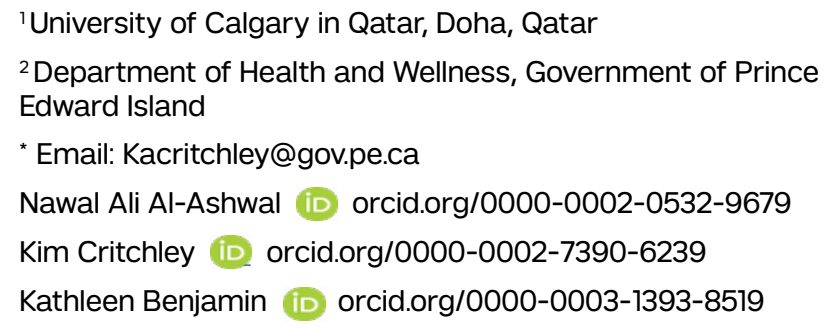

\section{Cite this article as:}

Al-Ashwal NA., Critchley K, Benjamin K. Cardiac rehabilitation programs: An investigation into the reasons for non-attendance in Qatar. 2017:2. http://dx.doi.org/10.20421/ighpe2017.02

This is an open access article distributed under the terms of the Creative Commons Attribution license CC BY 4.0, which permits unrestricted use, distribution and reproduction in any medium, provided the original work is properly cited. 
be sedentary and consume unhealthy diets. ${ }^{4}$ For these reasons, reserachers continue to look for ways to prevent mortality from cardiac diseases.

\section{Benefits and barriers of cardiac rehabilitation (CR) programs}

Authors have reinforced the importance of CR programs through identifying the main benefits of these programs. At the individual level benefits include: decreased mortality and incidence of CVD, improved exercise tolerance, reduction in smoking, risk factor modification, increased functional capacity, decreased depression, and improved psychosocial well-being and quality of life..$^{5-11}$ For instance, results of a study that compared the mortality rate among patients who received exercise therapy versus only medical care, revealed a $12 \%$ decrease in mortality due to cardiovascular death among patients who received exercise therapy. ${ }^{12}$ Participation in CR programs can also result in significant improvement in medication compliance ${ }^{13}$ and self-management among patients with CVD. ${ }^{14}$ At the organizational level, the benefits included fewer general practitioner contacts and hospital readmissions and reduced health care costs. ${ }^{15}$ However, despite the many benefits of CR programs, the literature shows that CR programs are underutilized.

Barriers reported in the literature included: lack of transportation, low social economic status, and knowledge deficits. ${ }^{16,17}$ Variables that are associated with a lower attendance rate are: older age, female gender and ethnicity. ${ }^{18-21}$

\section{Methods}

\section{Objective/research question}

The main objective of this study was to examine the barriers that prevent cardiac patients from participating in a CR program. The research question was: what are the reasons why a high percentage of referred cardiac patients to the CR program phase II do not attend the CR program in Qatar?

\section{Design/sample/recruitment}

This was a descriptive, quantitative, cross-sectional study that used a convenient sample of cardiac patients who were referred to the $\mathrm{CR}$ program Phase II in Qatar but who did not attend. A total of 1560 patients were referred from 1 January 2015 to 30 August 2015 and 54\% ( $N=850)$ of these patients did not attend the program. The target population were these 850 cardiac patients who were referred but who did not attend.

Due to time constraints for the first author to complete her Master thesis, 150 participants was determined to be a feasible and pragmatic sample size. Inclusion criteria were: 1) male or female who was referred to the CR program (Phase 11) in Qatar but who did not attend the CR program; 2) able to speak and understand English, and 3) provides verbal consent to participate in the study. Exclusion criteria were: 1) male and female who attended some or all of the CR sessions (Phase II); 2) unable to speak or understand English, and 3) unwilling to provide verbal consent.

After receiving ethical approval from a University and a hospital ethics board, the researcher obtained written permission to access the department registry at the study site to obtain patients' contact information. This registry lists the patients who were referred to $\mathrm{CR}$ and those who did not attend. A screening/recruitment script, consent and demographic questions were developed for this study. Potential participants were telephoned by the researcher and were screened using the recruitment script. If the participant met the inclusion criteria and was interested in participating a verbal consent was obtained.

Figure 1 provides a flow diagram of the recruitment process. Out of a potential pool of 850 participants who were referred to the CR program but did not attend, 793 participants were excluded. Reasons for exclusion were: did not speak English $(n=258)$, unable to contact the individual by phone (e.g., incorrect mobile number) $(n=453)$, and other reasons $(n=82)$. The resulting sample included 57 eligible participants. Eleven of these 57 participants refused to participate. Hence, the final sample included 46 participants.

\section{Data collection}

Data collection was completed in a 2-month period in 2016, using a telephone survey. The survey included 9 socio-demographic questions and 


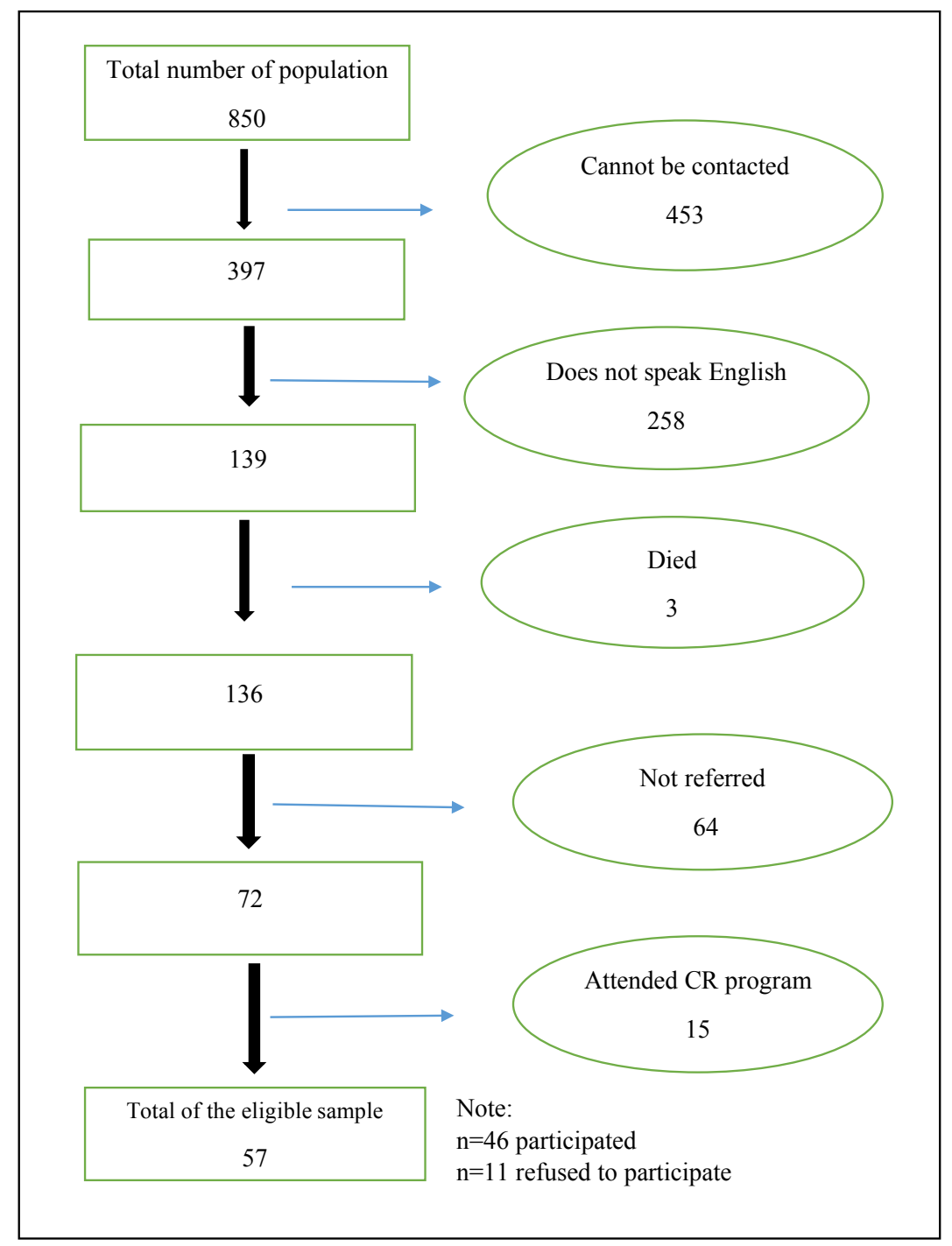

Figure 1. Flow diagram of recruitment.

questions from a pre-existing validated tool called The Cardiac Rehabilitation Barrier Scale (CRBS). ${ }^{22}$ The CRBS includes 21 items measured on a 5 point likert scale (endpoints: strongly disagree to strongly agree) and 1 open-ended question that asks participants for "other" reasons for not attending a CR program.

Grace ${ }^{18,19}$ performed psychometric testing of the CRBS and reported a significant correlation coefficient $=0.64(p<0.001)$, indicating reliability of the instrument. Similarly, the criterion validity was established for the 4 subscales. The Cronbach's a were: first subscale (Health Care Factors) $=0.89$; second subscale (Logistical Factors) $=0.88$; third subscale (Work/time Conflicts) $=0.71$; and fourth subscale (Comorbidities/functional Status) $=0.83$. The CRBS scale reliability was also tested in one additional study. ${ }^{22}$ The Cronbach's $\alpha$ of 0.91 suggests good reliability. The CRBS has been used in a number of different studies using mail out surveys. ${ }^{17-19}$

\section{Ethical considerations}

The researcher explained the study purpose and risks/benefits to the participants prior to obtaining verbal consent. Participants were advised that their participation was strictly voluntary and if they felt 
uncomfortable at any time, they could ask to stop the telephone survey. Various measures were used to maintain the participants' privacy and confidentiality. Telephone surveys were conducted in a private room; participants' names were not recorded on the paper survey and unique identifiers were used. All electronic data was stored on a password protected computer which was stored in a locked office. The master list containing the participant's contact information was kept in cabinet separate from other data. All hard and soft copy data will be retained for five years after completion of the study all data will be destroyed by shredding paper copies and erasing the data from the computer.

\section{Data analysis}

Unique variable codes were generated for each question item on the CRBS and entered into the statistical package for the social science program (IBM SPSS Statistics V20.0.0). The entered data was checked for completeness and quality (all entries match responses on the questionnaire). Univariate analyses provided an output summarizing frequency of response for all items. The output helped to locate errors and outliers that would have emerged from data entry.

Initially, appropriate labels were assigned to the fivepoint response categories for each of the 21 CRBS items as follows: 1 "Strongly Disagree"; 2 "Disagree"; 3 "Neither Agree or Disagree"; 4 "Agree"; 5 "Strongly Agree". Descriptive statistics (means, standard deviation and frequencies) was calculated for the 21 items and the nine socio-demographic items (i.e., age, gender, nationality, length of stay in Qatar, marital status, religion, education, employment and salary per month). The outputs from analysis were used to plot graphics and to summarize findings in a tabular format. Content analysis was employed to analyse the textual data from the one open ended question that asked participants for "other" reasons for not attending the CR program.

\section{Results}

\section{Socio-demographics}

Forty-six individuals agree to participate in the study The mean age of participants was 48.6 years (range 19-77 years). The majority of participants
(73.9\%) were over 40 years of age, and most were male (93.5\%). Nearly one-third (32.6\%) of the sample were of Indian nationality, $21.7 \%$ were Qatari, and $45.7 \%$ were "other" nationalities. Nearly one-half of the participants (43.5\%) reported residing in Qatar for more than 10 years. Most participants (93.5\%) were married (93.5\%) and 56.5\% reported living with their families. Nearly one-half $(47.8 \%)$ of the participants were Muslim, 32.6\% were Christian, and $19.6 \%$ were Hindu. The majority of participants (67.4\%) had a university education. Most of the participants (82.6\%) worked full-time and $41.3 \%$ reported a salary of less than QAR10,000 per month. Fifty percent of the participants reported living a short distance (i.e., 11-20 km) from the hospital that provided the CR program. Participants' responses are illustrated in Figure 2 and a summary is provided below.

1. More than one-half of the participants (56.5\%) agreed/strongly agreed that they did not attend the CR program because of work responsibilities, $41.3 \%$ strongly disagreed/ disagreed, and $2.2 \%$ neither agreed/disagreed with this statement.

2. Fifty percent of participants agreed/ strongly agreed that they did not attend the CR program because of time constraints, $43.5 \%$ strongly disagreed/disagreed, and $6.5 \%$ neither agreed /disagreed with this statement.

3. More than one-third of participants (39.1\%) agreed/strongly agreed that they did not attend the CR program because they already exercise at home or in the community, $52.2 \%$ strongly disagreed/disagreed, and $8.7 \%$ neither agreed /disagreed with this statement.

4. More than one-third of participants (39.1\%) agreed/strongly agreed that they did not attend the CR program because of the distance to the CR program, 56.5\% strongly disagreed/disagreed, and $4.3 \%$ neither agreed/ disagreed with this statement.

5. Nearly one-third of participants (32.6\%) agreed/strongly agreed that they did not attend the CR program because of traveling, 


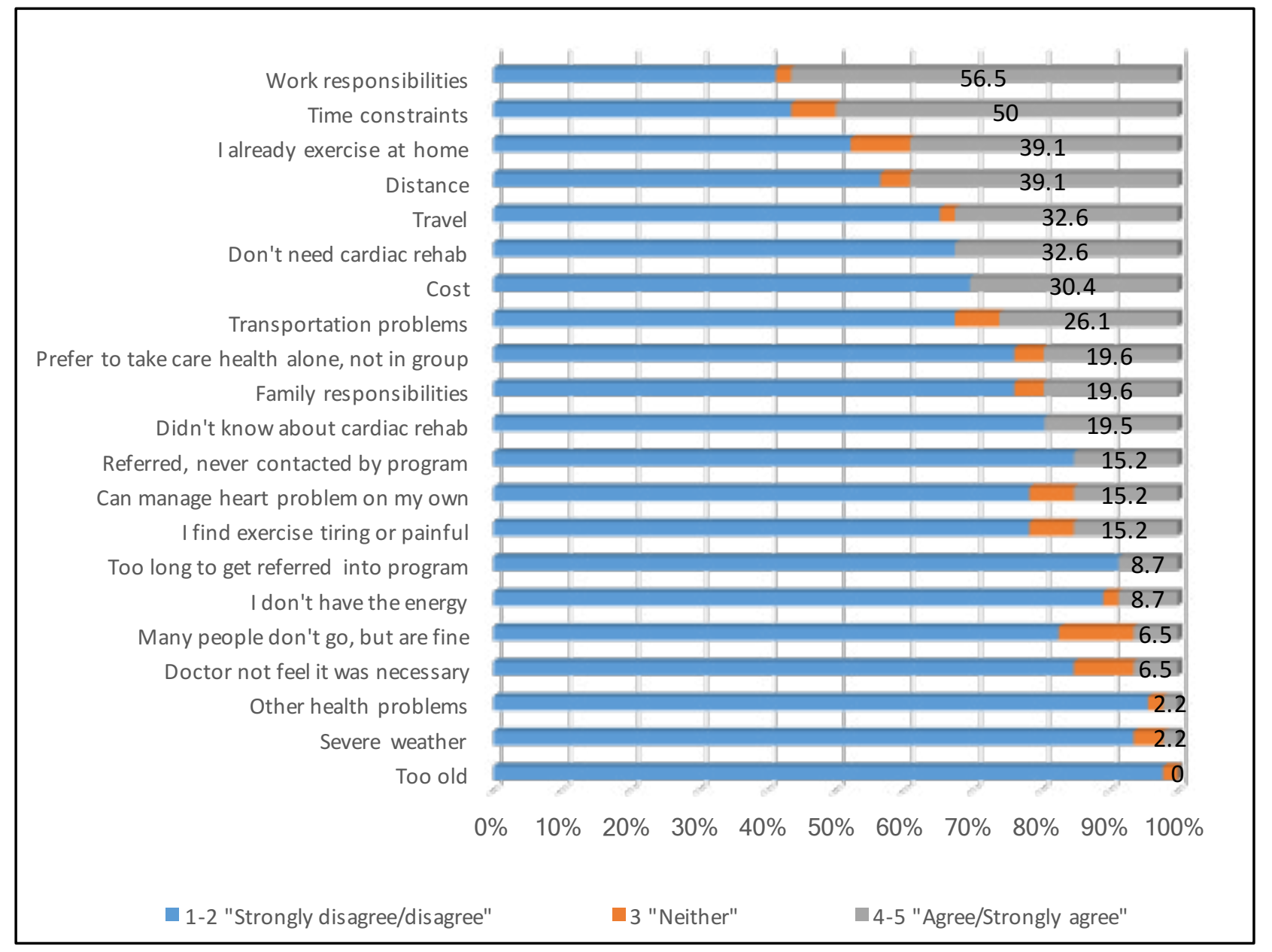

Figure 2. Reasons for not attending the CR program as per items on the CRBS.

$65.3 \%$ strongly disagreed/disagreed, and $2.2 \%$ neither agreed/disagree with this statement.

6. Nearly one-third of participants (32.6\%) agreed/strongly agreed that they did not attend the CR program because they do not need CR, and $67.4 \%$ strongly disagreed/ disagreed with this statement.

7. Nearly one-third of participants (30.4\%) agreed/strongly agreed that they did not attend the CR program because of cost and $69.5 \%$ strongly disagreed/disagreed with this statement.

8. About one-quarter of participants (26.1\%) agreed/strongly agreed that they did not attend the CR program because of transportation problems, $67.4 \%$ strongly disagreed/ disagreed, and $6.5 \%$ neither agreed /disagreed with this statement.

9. Less than one-quarter of participants (19.6\%) agreed/strongly agreed that they did not attend the CR program because they prefer to take care of their health alone and not in a group, $76.1 \%$ strongly disagreed/disagreed, and $4.3 \%$ neither agreed /disagreed with this statement.

10. Less than one-quarter of participants (19.6\%) agreed/strongly agreed that they did not attend the CR program because of family responsibilities, $76.1 \%$ strongly disagreed/ 
disagreed, and 4.3\% neither agreed /

disagreed with this statement.

11. Less than one-third of participants (19.5\%) agreed/strongly agreed that they did not attend the CR program because they did not know about CR, and $80.5 \%$ strongly disagreed/disagreed with this statement.

12. Less than one-third of participants (15.2\%) agreed/strongly agreed that they did not attend the CR program because the $\mathrm{CR}$ program did not contact them, and $84.8 \%$ strongly disagreed/disagreed with this statement.

13. Less than one-quarter of participants (15.2\%) agreed/strongly agreed that they did not attend the CR program because that they can manage their heart problem on their own, 78.3\% strongly disagreed/disagreed, and $6.5 \%$ neither agreed/disagreed with this statement.

14. Less than one-quarter of participants (15.2\%) agreed/strongly agreed that they did not attend the CR program because they find exercise tiring or painful, 78\% strongly disagreed/disagreed, and 6.5\% neither agreed/disagreed with this statement.

15. Only $8.7 \%$ of participants agreed/strongly agreed that they did not attend the CR program because it took long to get referred to the program, and $91.3 \%$ strongly disagreed/ disagreed with this statement.

16. Only $8.7 \%$ of participants agreed/strongly agreed that they did not attend the CR program because they do not have the energy, 89.1\% strongly disagreed/disagreed, and $2.2 \%$ neither agreed/disagreed with this statement.

17. Only $6.5 \%$ of participants agreed/strongly agreed that they did not attend the CR program because many people with heart problems do not go and they are fine, $82.6 \%$ strongly disagreed/disagreed, and $10.9 \%$ neither agreed/disagreed with this statement.
18. Only $6.5 \%$ of participants agreed/strongly agreed that they did not attend the CR program because their doctor did not feel it was necessary to participate in the $\mathrm{CR}$ program, 84.8\% strongly disagreed/disagreed, and $8.7 \%$ neither agreed /disagreed with this statement.

19. Only $2.2 \%$ of participants agreed/strongly agreed that they did not attend the CR program because of other health problems, $95.7 \%$ strongly disagreed/disagreed, and $2.2 \%$ neither agreed/disagreed with this statement.

20. Very few participants (2.2\%) agreed/ strongly agreed that they did not attend the CR program because of severe weather, 93.5\% strongly disagreed/disagreed, and 4.3\% neither agreed /disagreed with this statement.

21. Most of the participants (97.8\%) strongly disagreed/disagreed that they did not attend the CR program because they were too old, and $2.2 \%$ neither agreed /disagreed with this statement.

The major categories that emerged from the responses to the open-ended question were: work responsibilities, fatigue, distance, no need, out of country, and other reasons.

\section{Discussion}

\section{Work responsibilities}

More than one-half of the participants strongly agreed/agreed that they did not attend the CR program because of work responsibilities. This finding can be understood when considering the context of Qatar. The population of Qatar has 5 times more males than females. ${ }^{23}$ Many of these people are young males who come to Qatar from various countries to work on infrastructure projects (e.g., construction of the new rail system in Qatar). Other workers (often referred to as expatriates) are employed in areas such as retail, food services, middle and upper management. Qatar Sponsorship or the Kafala system is a system that regulates the admission of all expatriates, their departure from 
Qatar, the length of their residence in Qatar, and the terms of their sponsorshi. ${ }^{24}$ Workers who come to Qatar must be sponsored by their employers ${ }^{24}$ and adhere to the terms of a formal contract that is drawn up by the employer based on the Qatar Sponsorship rules and regulations.

Some of the participants commented that it was difficult for them to get release time from their work responsibilities and others felt that their request for release time could impact negatively on their position. Similar findings have been reported in the literature. Studies have found work responsibilities to be reported as a barrier to attending CR programs. ${ }^{19,25}$ The participants in this study reported that their work conflicted with the scheduled time of the exercise sessions. This finding has implications for future practice and research in Qatar. Currently, the CR program is only provided at one location (Doha) in Qatar. Even though the CR program is provided during working hours and in the evenings, participants find it difficult to attend the program. Some participants reported that they were not aware about the availability of evening sessions.

Education of participants about the availability of the evening classes is important. Some reported that shift work made it very difficult to attend the CR program. Providing CR programs on Saturday and having a more flexible schedule should be considered. This may help to increase the number of people who attend CR programs. There is a need for future qualitative research that will explore the context related to how "work responsibilities" act as a barrier.

\section{Time constraints}

Fifty percent of the participants strongly agreed/ agreed that they did not attend the CR program because of time constraints. This is not a surprising finding since most of the participants worked full time. Similar to other studies time constraints was a common reported barrier for not attending a CR program. ${ }^{19,26}$ Future qualitative research would help to better understand why these predominately male CR patients living in Qatar felt that time constraints acted as a barrier. This added knowledge can then be used to inform the development of strategies that would help minimize this barrier.

\section{Already exercise at home/community}

More than one-third (39.1\%) of the participants strongly agreed/agreed that they did not attend the $\mathrm{CR}$ program because they already exercise at home or in the community. Other studies have reported similar results. In two studies ${ }^{25,27}$ participants indicated that they did enough exercise at home and that there was no need for them to attend a $\mathrm{CR}$ program. These findings have implications for practice and research. First, there is a need to educate cardiac patients about CR programs. Patients need to be aware that CR programs include not only exercise but other components such as medication, diet and lifestyle management. Also, there is a need to determine if the participants who said they were already exercising at home were exercising safely and at an intensity, frequency and duration to realize the health benefits from exercise. Future research could examine cardiac patients' knowledge related to optimal level and type of physical activity that is needed to achieve health benefits. In Qatar 'Physical Activity Guidelines for people coronary artery disease" have been developed ${ }^{28}$ which could be used as an educational tool.

\section{Distance}

More than one-third (39.1\%) of the participants agreed/strongly agreed they did not attend the CR program because of distance despite the fact that one-half of the participants lived only $11-20 \mathrm{~km}$ from the hospital that provided the CR program. Other studies have also documented distance as a barrier to attendance at CR programs. ${ }^{17,26,27,29}$ For example, Shanmugasegram et al. ${ }^{17}$ found that participants who live in a rural setting, (defined as the distance of a 30 minute drive) were significantly less likely to participate in a CR program compared to participants living in an urban setting.

The finding of this study needs to be understood within the context of Qatar. The CR program is provided in the capital city of Qatar (Doha). There is considerable traffic congestion in Doha and travelling just short distances can take 1-2 hours because of the traffic congestion. According to Planells and Griffin ${ }^{30}$ the main reason for traffic congestion in Qatar is related to the 7\% annual 
increase in the population in Qatar and the 10\% annual increase in traffic since 2010. Despite new road development, it has not been enough to accommodate for this rapid growth in the population of Qatar. ${ }^{30}$ These finding have implication for future practice. There is a need to consider providing CR programs in areas that have less traffic congestion and more parking. Also, CR programs should be provided at hours when there is less traffic congestion.

\section{Travel}

Nearly one-third of the participants (32.6\%) in this study agreed /strongly agreed that they did not attend the CR program because of travel. Some of the participants commented that they had to travel outside of Qatar for holidays, business or to visit family which prevented them from attending the CR program. Participants explained that when they obtained leave from their sponsor they travelled to other countries to be close to their families or to be cared by their family members. Furthermore, because some participants viewed attending a CR program as optional, they did not feel that it was important to return to Qatar to attend the CR program. Similarly, in a Canadian study some participants reported personal travel as one of the reasons that prevented them from attending a CR program.$^{27}$ There is a need to educate cardiac patients on the importance of engaging in $\mathrm{CR}$ following a cardiac event. This may lead to quicker recovery, less reoccurrence of a cardiac event and overall better health outcomes.

\section{Do not need to attend}

Nearly one-third (32.6\%) of the participants agreed / strongly agreed reported that they did not need to attend a CR program. Other studies have reported similar findings. In a study by Grace et al. ${ }^{18}$ participants reported that their condition was not serious enough to warrant attendance at a CR program and they believed that the CR program would not improve their condition. In another study, participants aged 40 to 65 years of age with low socioeconomic status, believed that it was their destiny to have cardiac disease and no intervention was needed to improve their condition. ${ }^{31}$ In a Jordanian study, participants believed that it was God's will for them to have cardiac disease, that exercise would not improve their condition, and that there was not anything that they could do to improve their condition. ${ }^{32}$ Comments made by some of the participants in this study provides insights as to why they did not believe in the need to attend CR. Some participants believed that their cardiac disease was temporary, while other participants believed that the heart is just a muscle in the body, and like other muscles that become injured, the heart would repair itself. These findings suggest that there is a need to develop educational programs that will address issues related to heart health, risk factors for heart disease and the important benefits of attending a CR program.

\section{Limitations/challenges}

This study faced challenges worth discussing. By adopting a telephone survey mode for this study, we had hoped to reach most of the potential participants. However, this was not the case. First, over half of potential participants could not be reached through the phone numbers on the registry. This was likely because the phone numbers had been changed or were was no longer in service. The numbers were obtained from the patients in 2015. Second, a quarter of the potential participants were excluded due to inability to speak English. This constitutes a potentially large pool of eligible participants whose opinions on the CRBS would have contributed to the findings. This exclusion criteria introduced a selection bias, thus, findings need to be interpreted with caution as they cannot be generalized to represent the opinions of participants in the CR program. Third, since most of the participants were male (93.5\%), the results do not show the female perspective. Lastly, the sample size was small $(n=46)$. As such, the use of this survey tool may not have adequately captured data related to other important factors that can influence a patients' decision to enter a CR program. For example, it has been previously reported that the strength of primary physicians' recommendations for participation was the most powerful predictor of cardiac rehabilitation entry. ${ }^{33}$ Similarly, having received advice to exercise for their physician was a significant predictor influencing the exercise decisions of seniors. ${ }^{34}$ Future researchers should consider asking participants questions related to physician recommendations and how these recommendations influenced their decisions to participate/not to participate in CR. Nonetheless, 
the findings shed light on the CR program and can help inform future studies.

\section{Conclusion}

This research is the first study to examine the reasons why cardiac patients in Qatar do not attend a CR program. Similarities and differences to the international literature were found. The most frequently reported reason for not attending a CR program was work responsibilities. Much of this can be explained through understanding the rules and regulations around the Qatar Sponsorship or Kafala system that requires non-nationals living in Qatar to be employed full time. ${ }^{24}$ It is important to note that most of the participants in this study were male and were from other countries and nationalities, other than Qatari. The Kafala system stipulates that in order for these non-nationals to stay in the State of Qatar, they are required to be sponsored by an employer. If they do not work, they cannot be sponsored, and they would be required to leave the country. ${ }^{24}$ Travel out of the country to visit family was a unique barrier found in this study. This finding is likely related to the fact that most of the participants are expatriates and many have family members that live outside Qatar. There is a need for CR programs to add bridges and form linkages with other vital health and fitness facilities located in Qatar. Patients are not accessing the $\mathrm{CR}$ programs due to a variety of reasons. Therefore, the responsibility to provide programs that are readily accessible rests with the health care providers.

Acknowledgements: The first author would like to thank several people at the Heart Hospital. She would like to thank Professor William John McKenna for his support for this study. A special thank you to Dr. Cornelia Sonia Carr, senior consultant Cardiothoraic Surgery and Dr. Amer Salah Elsid, consultant of Anaesthesia and Intensive care unit, and assistant professor Weill Cornell Medical College in Qatar for influencing me through their extensive experience and interest in this field of research. In addition, the first author would especially like to thank all of the study participants who were most generous with their time and graciously shared information about their experience of not attending a CR program.

Conflicts of interest: None.
Funding sources: Qatar National Research Fund through Project (NPRP \# 6-049-3-009).

\section{References}

1. Bener A, Al-Suwaidi J, Al-Jaber K, Al-Marri $\mathrm{S}$, Elbagi IE. Epidemiology of hypertension and its associated risk factors in the Qatari population. J Hum Hypertens. 2004 Jul;18(7):529-30. doi: 10.1038/sj.jhh.1001691.

2. Noncommunicable diseases [Internet]. Geneva, Switzerland: World Health Organization; 2017 [updated 2017 Jun; cited 2017 Dec 7]. Available from: http://www.who. int/mediacentre/factsheets/fs355/en/

3. Donnelly TT, AI Suwaidi JM, Alqahtani A, Assad N, Qader NA, Byrne C, et al. Study exploring depression and cardiovascular diseases amongst Arabic speaking patients living in the State of Qatar: Rationale and methodology. Glob Cardiol Sci Pract [Internet]. 2012 Jan[cited 2017 Dec 7]; (2):5666. Available from: https://doi.org/10.5339/ gcsp.2012.24

4. Musaiger AO. The Food Dome: dietary guidelines for Arab countries. Nutr Hosp [Internet]. 2012 Jan-Feb [cited 2017 Dec 7]; 27(1):109-15. Available from: http://scielo.isciii. es/scielo.php?script=sci_arttext\&pid=S0212$16112012000100012 \& \operatorname{lng}=$ en\&nrm=iso\&tlng=en doi: 10.1590/s0212-16112012000100012

5. Blair J, Angus NJ, Lauder WJ, Atherton I, Evans $J$, Leslie SJ. The influence of non-modifiable illness perceptions on attendance at cardiac rehabilitation. Eur J Cardiovasc Nurs. 2014 Feb;13(1):55-62. doi: 10.1177/1474515113477272.

6. Canadian guidelines for cardiac rehabilitation and cardiovascular disease prevention. 3rd ed. Winnipeg, MB: Canadian Association of Cardiac Rehabilitation; 2009. 539 p.

7. Leon AS, Franklin BA, Costa F, Balady GJ, Berra KA, Stewart KJ, et al. Cardiac rehabilitation and secondary prevention of coronary heart disease: an American Heart Association scientific statement 
from the Council on Clinical Cardiology (Subcommittee on Exercise, Cardiac Rehabilitation, and Prevention) and the Council on Nutrition, Physical Activity, and Metabolism (Subcommittee on Physical Activity), in collaboration with the American association of Cardiovascular and Pulmonary Rehabilitation. Circulation [Internet]. 2005 Jan 25 [cited 2017 Dec 7]; 111(3):369-76. Available from: https://doi.org/10.1161/01. cir.0000151788.08740

8. Mampuya WM. Cardiac rehabilitation past, present and future: an overview. Cardiovasc Diagn Ther [Internet]. 2012 Mar [cited 2017 Dec 7]; 2(1):38-49. Available from: https://doi. org/10.3978/j.issn.2223-3652.2012.01.02

9. McAlister FA, Lawson FM, Teo KK, Armstrong PW. Randomised trials of secondary prevention programmes in coronary heart disease: systematic review. BMJ [Internet]. 2001 Oct 27 [cited 2017 Dec 7]; 323(7319):95762. Available from: https://doi.org/10.1136/ bmj.323.7319.957

10. McKee G, Kerins M, Fitzgerald G, Spain M, Morrison K. Factors that influence obesity, functional capacity, anxiety and depression outcomes following a Phase III cardiac rehabilitation programme. J Clin Nurs. 2013 Oct;22(19-20):2758-67. doi: 10.1111/jocn.12233.

11. Taylor RS, Brown A, Ebrahim S, Jolliffe J, Noorani H, Rees K, et al. Exercise-based rehabilitation for patients with coronary heart disease: systematic review and meta-analysis of randomized controlled trials. Am J Med. 2004 May 15;116(10):682-92. doi: 10.1016/j. amjmed.2004.01.009.

12. Oldridge NB, Guyatt GH, Fischer ME, Rimm AA. Cardiac rehabilitation after myocardial infarction. Combined experience of randomized clinical trials. JAMA. 1988 Aug 19;260(7):945-50.

13. Guidelines for cardiac rehabilitation and secondary prevention programs. 5th ed. Champaign, IL: Human Kinetics; 2013. 336 p.
14. Cleary KK, LaPier TK, Beadle C. Exercise adherence issues, behavior change readiness, and self-motivation in hospitalized patients with coronary heart disease. J Acute Care Phys Ther. 2011 Summer;2(2):55-63. doi: 10.1097/01592394-201102020-00002.

15. Heran BS, Chen JM, Ebrahim S, Moxham T, Oldridge N, Rees K, et al. Exercise-based cardiac rehabilitation for coronary heart disease. Cochrane Database Syst Rev [Internet]. 2011 Jul 6 [cited 2017 Dec 7]; (7):Cd001800. Available from: https://www. ncbi.nlm.nih.gov/pmc/articles/PMC4229995/

16. Almerud Osterberg S, Baigi A, Bering C, Fridlund $B$. Knowledge of heart disease risk in patients declining rehabilitation. Br J Nurs [Internet]. 2010 Mar 11-24 [cited 2017 Dec 7]; 19(5):288-93. Available from: https://doi. org/10.12968/bjon.2010.19.5.47060

17. Shanmugasegaram $S$, Oh P, Reid RD, McCumber T, Grace SL. Cardiac rehabilitation barriers by rurality and socioeconomic status: a cross-sectional study. Int J Equity Health [Internet]. 2013 [cited 2017 Dec 7]; 12:72. Available from: https://doi.org/10.1186/14759276-12-72

18. Grace SL, Gravely-Witte S, Kayaniyil S, Brual J, Suskin N, Stewart DE. A multisite examination of sex differences in cardiac rehabilitation barriers by participation status. J Womens Health (Larchmt) [Internet]. 2009 Feb [cited 2017 Dec 7]; 18(2):209-16. Available from: https://doi.org/10.1089/jwh.2007.0753

19. Grace SL, Shanmugasegaram S, GravelyWitte S, Brual J, Suskin N, Stewart DE. Barriers to cardiac rehabilitation: does age make a difference? J Cardiopulm Rehabil Prev [Internet]. 2009 May-Jun [cited 2017 Dec 7]; 29(3):183-7. Available from: https://insights. ovid.com/pubmed?pmid=19471138

20. Mochari $H$, Lee JR, Kligfield $P$, Mosca L. Ethnic differences in barriers and referral to cardiac rehabilitation among women hospitalized with coronary heart disease. Prev Cardiol. 2006 Winter;9(1):8-13. 
21. Sanderson BK, Shewchuk RM, Bittner V. Cardiac rehabilitation and women: what keeps them away? J Cardiopulm Rehabil Prev. 2010 Jan-Feb;30(1):12-21. doi: 10.1097/ HCR.0b013e3181c85859.

22. Shanmugasegaram $S$, Gagliese $L$, Oh P, Stewart DE, Brister SJ, Chan V, et al. Psychometric validation of the Cardiac Rehabilitation Barriers Scale. Clin Rehabil [Internet]. 2012 [cited 2017 Dec 7]; 26(2):152-64. Available from: https://doi. org/10.1177/0269215511410579

23. Bel-Air FD. Demography, migration, and labour market in Qatar (Explanatory Note No. 8). Geneva, Switzerland: Gulf Research Center; 2014 [cited 2017 Dec 7]. Available from: http://gulfmigration.eu/demographymigration-and-labour-market-in-qatar /

24. Qatar's fourth national human development report: realising Qatar national vision 2030 the right to development. Doha, Qatar: Ministry of Development Planning and Statistics; 2015 [cited 2017 Dec 7]. Available from: https://www.mdps.gov.qa/en/ knowledge/Doc/HDR/Qatar Fourth National HDR_Realising_QNV2030_The_Right_to_ Development 2015 EN.pdf

25. Poh R, Ng HN, Loo G, Ooi LS, Yeo TJ, Wong $\mathrm{R}$, et al. Cardiac Rehabilitation After Percutaneous Coronary Intervention in a Multiethnic Asian Country: Enrollment and Barriers. Arch Phys Med Rehabil. 2015 Sep;96(9):1733-8. doi: 10.1016/j. apmr.2015.05.020.

26. De Vos C, Li X, Van Vlaenderen I, Saka O, Dendale $P$, Eyssen $M$, et al. Participating or not in a cardiac rehabilitation programme: factors influencing a patient's decision. Eur J Prev Cardiol. 2013 Apr;20(2):341-8. doi: $10.1177 / 2047487312437057$.

27. de Melo Ghisi GL, Oh P, Benetti M, Grace SL. Barriers to cardiac rehabilitation use in Canada versus Brazil. J Cardiopulm Rehabil Prev. 2013 May-Jun;33(3):173-9. doi: 10.1097/ HCR.0b013e3182930c9f.
28. The State of Qatar national physical activity guidelines. Doha, Qatar: Aspetar; 2014 [cited 2017 Dec 7]. Available from: https://www. namat.qa/Namat/mages/Publications/75/ QATAR PA GUIDLINE ENGLISH.PDF

29. De Angelis C, Bunker S, Schoo A. Exploring the barriers and enablers to attendance at rural cardiac rehabilitation programs. Aust J Rural Health. 2008 Jun;16(3):137-42. doi: 10.1111/j.1440-1584.2008.00963.x.

30. Planells CR, Griffin I. Traffic congestion in Doha: causes and solutions. Qatar Constr News [Internet]. 2014 Nov [cited 2017 Dec 7]; (1.3). Available from: http:// www.qatarconstructionnews.com/trafficcongestion-doha-causes-solutions/

31. Savage M, Dumas A, Stuart SA. Fatalism and short-termism as cultural barriers to cardiac rehabilitation among underprivileged men. Sociol Health IIIn. 2013 Nov;35(8):1211-26. doi: 10.1111/1467-9566.12040.

32. Al-Ali N, Haddad LG. The effect of the health belief model in explaining exercise participation among Jordanian myocardial infarction patients. J Transcult Nurs. 2004 Apr;15(2):114-21. doi: $10.1177 / 1043659603262484$.

33. Ades PA, Waldmann ML, McCann WJ, Weaver SO. Predictors of cardiac rehabilitation participation in older coronary patients. Arch Intern Med. 1992 May;152(5):1033-5. doi: 10.1001/archinte.1992.00400170113021.

34. Benjamin K, Edwards NC, Bharti VK. Attitudinal, perceptual, and normative beliefs influencing the exercise decisions of community-dwelling physically frail seniors. J Aging Phys Act. 2005 Jul;13(3):276-93. doi: 10.1123/japa.13.3.276. 